\title{
Recombinant Interleukin-14
}

National Cancer Institute

\section{Source}

National Cancer Institute. Recombinant Interleukin-14. NCI Thesaurus. Code C1630.

A recombinant peptide, which is chemically identical or similar to the endogenous cytokine interleukin-14 (IL-14). The cytokine inhibits immunoglobulin secretion and selectively expands activated B-cell subpopulations. An IL-14 receptor is found on activated B-cells, but not in resting B-cells. This agent is unrelated to other cytokines but has homology with complement factor Bb. Autocrine or paracrine production of IL-14 may play a significant role in the rapid proliferation of aggressive non-Hodgkin lymphoma (NHL-B). Interrupting this pathway could be a useful goal of therapy for patients resistant to conventional chemotherapy. 